\title{
Mediatheorie van het e-book
}

\author{
Arjen Mulder
}

\section{ABSTRACT}

Departing from Marshal McLuhan's analysis of the impact of print books on the mental and social environment of readers, Arjen Mulder reflects on the possible mental and social effects of the e-book as a new medium. The e-book, as carrier of an immaterial text, allows the reader to change its lay-out, font and other design elements. Additionally, e-books contain not just one single novel but an entire library and even contain an online bookstore. Another prominent effect of e-books is that they cause discrepancies between the actual reading experience and the user experience of the medium. Mulder also analyses some of the disadvantages of this new medium due to its technical properties. These concern for instance the integrity of the text, the unreliability of the technology, or the fact that providers can without any permission reinitialise your e-reader and therewith delete your entire e-book library. Mulder concludes with a discussion of the different reading modes available to readers to read print and electronic texts.

\section{VRAAGSTELLING}

Volgens de grondlegger van de mediatheorie, Marshall McLuhan, is de boodschap van elk bericht het medium waarmee dat bericht wordt verzonden. Niet de overgedragen inhoud is van belang voor de mediatheorie, maar de wijze van overdracht en de effecten die het communicatiemedium zelf heeft op de gebruikers, mentaal, sociaal, politiek.

In zijn nog altijd duizelingwekkende The Gutenberg Galaxy (1962) toont McLuhan hoe de ontwikkeling van het alfabet in Griekenland tussen 800 en 400 v. C. culmineerde in de geschriften van de filosoof Plato, die als eerste het zo typisch westerse ik-besef uit het menselijk bewustzijn isoleerde en waardeerde. Bij het vertellen in orale culturen valt het verhaal min of meer samen met de verteller, net zoals de luisteraars bij de vertelling door mimesis en immersie geheel opgaan in wat ze beleven op de klank van de stem van de singer of tales. Als Plato zijn gedachten in lettertekens voor zich op papyrus ziet verschijnen, realiseert hij zich dat hijzelf, de denker, iets anders is dan wat hij denkt en als vertelling opschrijft. Afstand. Ik schrijf, dus ik ben.

Ook de lezer heeft heel andere ervaringen dan de luisteraar, zelfs bij hetzelfde verhaal. Als ik lees houdt iemand in mij in de gaten wat mij als lezer overkomt en hoe ik daarop reageer. Geen immersie maar suspension of disbelief. In mij zit iemand die de tekst die ik lees interpreteert en de betekenis ervan ontsluiert. Wie is die denker? Wat vormt de kern in mij, wat is het ik? Mijn onsterfelijke ziel, was Plato's onverschrokken antwoord. Ik en God vallen bij Plato min of meer samen. Beiden scheppen de wereld door haar in woorden uit te drukken op grond van ideeën.

Plato standaardiseert gelijk ook de filosofische denkmethode als het Socratisch gesprek. Redeneren, concluderen, implementeren. De rest is sofisterij. Het ik is de factor die het ons mogelijk maakt de maatschappij zo in te richten als wij haar wensen, en wij wensen haar zoals ze bedoeld is - door God. Dit goddelijk ik nu, deze zekerheid niet alleen in een lichamelijke maar ook in een geestelijke wereld te verkeren, is wat onder vuur komt te liggen met de opkomst van het nieuwe medium waarmee McLuhan zich in zijn tijd geconfronteerd ziet: de elektronische communicatiemiddelen, of wat we nu noemen het net.

$\mathrm{Na}$ alle eerdere extensies van onze zintuigen in technische apparaten-luidspreker de stem, de versterker het oor, verrekijker, film en tv het oog, parfum het geurveld rond de neus, peper de smaak - verlengt ons complete zenuwstelsel zich in de technische netwerken van telefoon en internet tot het de hele globe omvat, in iedereen geïnteresseerd raakt, alles mee kan voelen, overal aanwezig blijft op elk moment van de dag.

Ons ik, het eiland der ziel, is zelf een netwerk geworden, een samenstel van relaties, waarbij niet de hoedanigheid van de knopen van belang is, maar de frequentie waarmee bepaalde links wel en andere niet worden geactiveerd. Waarover winden wij ons op en wat laten we liever langs ons afglijden? Ons ik is vervangen door onze identiteit, ons profiel, het patroon dat uit onze data af te leiden valt. Het is constant online en lost op in de digita- 
le netwerken, die McLuhan eens en voor altijd op naam bracht als global village.

Het elektronische lezen op een e-reader of tablet vormt, in het licht van McLuhans duiding van de mediageschiedenis, een directe aanval op de verworvenheden van het gedrukte, papieren boek. Ons ik staat op het spel, onze onsterfelijke ziel, het breekbare riet waaraan we ons vastklampen in de stroom van de tijd. McLuhan trok religieuze consequenties uit dit inzicht en bekeerde zich tot de katholieke kerk, de hoeder van het boek bij uitstek, met de paus die per encycliek onfeilbaar de enig juiste interpretatie van een Bijbeltekst kan geven. Het papieren boek bevat een heilige boodschap en die luidt: jij leest dus jij bestaat. Een elektronische tekst is een stootje energie dat zich voortplant door een netwerk van losse contacten tot het onherkenbaar verdund is. Ja, er staat iets hoogs op het spel, als McLuhans mediatheorie klopt.

Stel dat McLuhans centrale idee, 'the medium is the message', correct is, dan zou het lezen van een boek op een e-reader een compleet andere leeservaring moeten oproepen dan het lezen van een gedrukt, vormgegeven, papieren boek met dezelfde tekst. Hoe anders precies? Dat is het onderwerp van mijn onderzoek hieronder. We maken het aan den lijve mee. Onderstaand verslag dateert uit de periode augustus 2013-november 2015 .

\section{MY FIRST E-READER}

De komst van de e-reader met daarop vele, liefst onbetaalde e-books heeft de status van het papieren boek ingrijpend veranderd. Het ziet zich van een medium in een object veranderd. De e-readerprofeten voorspelden een paar jaar terug het aanstonds verdwijnen van het o zo lompe papieren boek, al was hun marktaandeel toen nog geen drie procent, in één ding hadden ze gelijk. Een boek is nooit meer hetzelfde.

Het kan ook iets anders zijn dan een homp papier met een glimmende kaft, een jaszakgroot scherm waarop je de boektekst kunt lezen, zonder het geheel te hoeven overzien, zonder vooruit of terug te kunnen bladeren, want dat is me nogal een gedoe op de trage eerste generatie e-readers. Maar deze technische beperking is tegelijk een geestelijke verrijking, want doordat je alleen maar vooruit kunt lezen ontdek je veel sneller welke namen een schrijver herinnerbaar heeft weten te maken en welke niet, ondanks en dankzij de suffe software.

E-readen is als naar een verhaal luisteren dat iemand op een geïnspireerde avond vertelt. Je gaat erin mee zolang de spreker de verhaallijn zichzelf laat ontspinnen en de verteller niet méér weet dan zijn luisteraars. McLuhan voorspelt het al in
The Gutenberg Galaxy. De e-reader roept met elektronische middelen een ervaring op uit de orale cultuurfase van de mensheid, die duurde van 150.000 tot 4000 jaar v.C. Honderd generaties die alleen maar vooruit leefden, kringgang na kringgang zonder ooit iets vast te leggen op een stabiele, externe drager. Ons levende geheugen onthoudt niet letterlijk, maar semiotisch. De betekenis van wat we zeggen blijft actief, de algehele strekking. De exacte verwoording is per vertelling anders, althans niet gelijk aan de versie die nu, na het vertellen, meteen ook voorgoed is vervlogen.

Een boektekst is blijkbaar een bericht dat op elk digitaal platform kan verschijnen, en niet, zoals ik altijd dacht, een schatkamer van geestelijke afwezigheid en innerlijke concentratie op de waarheid die achter de tekst ligt, diep in de vezels van het geurende papier waarop het staat gedrukt. In een e-reader heeft een pagina geen voor- en achterkant meer, het blad is volkomen plat, eerder een boekrol dan een paperback.

De marketeers bedachten dat een e-book geen ruimte inneemt, anders dan een papieren boek dat altijd en onvermijdelijk een opslagprobleem oplevert. Het trotse boekenbezit dat langs de kamerwanden staat gerangschikt in elegante kasten of muurvullende, zelf aangebrachte planken - het is opeens ruimte die ook met andere spullen kunnen worden vol gezet, of leeg gelaten. Leegte is een luxe die je jezelf gunt, dus weg met die stoffige, knoestige papierwinkel die tot voor kort als privé-bibliotheek getuigde van intellectuele status, een literaire smaak en hoogstpersoonlijke voorkeuren en voornemens. Ik ben wat ik in mijn boekenkast heb staan.

Een gedrukt boek is deel van de geschiedenis, een persoonlijke maar ook sociaal-culturele historie. Een e-book is alleen heden, jouw tegenwoordige tijd. Amazon doet onderzoek of niet alle e-books met een derde kunnen worden ingekort, want 'e-lezers' blijken eigenlijk nooit verder te komen dan tweederde van de geleverde tekst. Een filosoof die zijn gedachtewereld niet in minder dan 5000 woorden kan uitleggen is een kletskous. Hegel bleek niet om door te komen op mijn e-reader, na 23 procent bleef ik steken. Aan Schellings kosteloos downloadable Weltgeist ben ik niet eens begonnen. Nog achttien uur Duitse redenaties te gaan.

Een e-reader is dus vooral een verzamelbak van onvoltooide projecten, relaties die vastliepen, verveling en weerzin. Net als een kast vol boeken, zou je zeggen. Het verschil is dat die boeken rustig in het volle zicht op je blijven wachten, terwijl je e-reader ze verdringt naar een Borgesiaanse uithoek van de draagbare universele bibliotheek, waar ze niet makkelijk meer uitkomen. Dat heb je met nog te gaan, in plaats van als ik er aan toe ben. 
Het papieren boek blijft bestaan, maar niet meer als ding dat in je sociale leven een functie vervult, dat je kunt meenemen en naar eigen inzicht gebruiken, aan anderen kunt onthullen of weggeeft. Wel als cultvoorwerp dat zorgvuldig in de privé-collectie achter glas wordt bewaard. Want het is z'n ruimte waard, de fraai geïllustreerde edities of de volmaakt harmonische samenhang tussen font, papier, tekst- en boekblok. Ik koop vaak boeken om hun karaktervolle uiterlijk, nieuw of tweedehands, gevonden of geruild.

De e-reader biedt zo bezien de oplossing voor een lelijke boekuitgave, die mij had weggehouden van Karl Ove Knausgårds Bildungsepos Mijn Strijd. Zonder de blikkerige omslag en in een stevige Georgia van gemiddelde lettergrootte las ik deel I, Vader, in de elektronische editie van dezelfde $\mathrm{Ne}$ derlandse uitgeverij. Deze typografie maakte het nogal omslachtige verhaal dat louter uit losse draadjes lijkt te bestaan, op den duur overtuigend. Toch is één deel van het epos wel genoeg. Als papieren boek zou ik het absoluut niet in de kast willen hebben. $\mathrm{Nu}$ zie ik geen reden tot verwijderen.

Stel dat het e-book ons sociale leven, na de revoluties van het schrift en de boekdrukkunst, nogmaals tot de bodem toe transformeert, één vervreemdingsronde verder, ditmaal weg van de cultuur van het herkenbare papieren boek naar de anoniem-intieme e-reader annex tablet. Wat krijg je dan? Living alone together in de zoveelste update? Waarom lezen als je ook direct kunt communiceren?

De samenleving die Vilém Flusser voorziet in zijn heerlijke In het universum van de technische beelden (1991), de door hem bejubelde dialogische wereld waarin iedereen continu met iedereen communiceert, heeft geleid tot een attention span van een seconde of negen. Alles wat meer dan een minuut van je aandacht eist is een geschenk dat je aan de maker teruggeeft voor zijn goede werk, haar humor. Kinderen die op dit moment worden geboren zullen op hun zevende al een compleet jaar aan het scherm vastgeplakt hebben gezeten, becijferde psycholoog Aric Sigman. Dat is gemiddeld 3,5 uur per dag. Hoeveel ben jij kwijt per dag? Tien, veertien uur?

Kwijt zou ik die tijd niet willen noemen. Maar toch. Hoeveel jaar van je leven heb je al achter een scherm doorgebracht? Waarom voelt het antwoord op die vraag een beetje benauwend, alsof het ons eraan herinnert dat er voorbij het beeldscherm ook nog een wereld bestaat die haar eisen stelt en haar schoonheden onthult? En waarom voel je je minder ellendig bij het idee dat je jaren van je leven hebt doorgebracht met Marcel Proust altijd binnen handbereik, of Hans Henny Jahnn, Uwe Johnson, A.F.Th. van der Heijden of een van de andere mega-oeuvrebouwers? Je moet duizend uur
Team Fortress of World of Warcraft spelen voor je er best goed in bent. Hoeveel gedichten moet je lezen voordat je iets van Hölderlin snapt, of van Kees Ouwens, of Jacob Groot, of Lucas Hüsgen?

Een boekpagina is materieel, een stabiele papieren drager-en wat een prachtig proces om dat te maken in de eeuwenoude papiermolen van Horni Lipova. De tekst is op dat papier in duurzame inkt gedrukt, de lettertekens kaarsrecht naast elkaar, regel na regel, een wonder van precisie. Er is er de klassieke Bembo-literatuur en de modernistische Helvetica-schrijver. Eigentijdse Calibri-poëzie. Een papieren boek bevat niet alleen informatie, zoals elektronische en digitale media, maar ook betekenis, georganiseerde informatie: een code die verwijst naar wat het boek zelf niet is, uitzicht op de wijde wereld, inzicht in de diepten van de ziel, beide in een geestelijk domein achter het tekstrooster. Ic was in mijn hoofkijn om cruyt gegaen. Een boek is een veeleisende minnaar, of vriendin. De relatie boek-lezer is pure mystiek. Eenzaamheid te midden van de massa, stilte midden in rumoer. Tegenwoordigheid van geest in een oceaan van afleiding. Valt dat te hermediëren op een elektronische drager?

Laten we de positieve kanten van de e-reader op onze vingers aftellen. Ten eerste de emancipatie van de lezer uit de klauwen van de grafisch ontwerper. Je mag zelf typografie, lettertype, regelafstand, regelval en font bepalen tot het boek voor jou persoonlijk leesbaar is gemaakt. Zo las ik op mijn kobo e-reader Adalbert Stifters negentiende-eeuwse Bildungsroman Der Nachsommer (1857) in een koele Gill Sans, een keihard, kraakhelder lettertje, als in marmer gebeiteld. De lettergrootte hield ik gering, de regelafstand minimaal. De marges een halve centimeter. Ik moest er mijn leesbril bij opzetten, maar dat beviel me juist, dat ritueel. Wij zagen in theehuis Der Albertsberg te Ladek-Zdroj in Zuid-Polen een dame een e-book lezen met een letter zo groot dat er amper vier woorden op het scherm pasten. Ik: Wat doet die nou? Maaike: Ze wil haar leesbril niet op in het openbaar.

Ik voegde een witregel in tussen de alinea's van Stifters traag stromende tekst. Der Meister der Langsamkeit is zijn eretitel. De witregels brachten adem in de gestaag voortkolkende vertelstroom. En dan snap je al snel wat Gertrude Stein bedoelt met haar dictum: 'A paragraph is emotional, a sentence is not.' Ik las Stifter in vaste regelval, een uitgevuld tekstblok, met als nadeel de vele onjuiste afbrekingen. Deze wekken langzaam maar zeker het besef dat lettergrepen er binnenkort niet meer toe zullen doen, want elk woord zal vloeibaar worden, alzijdig deelbaar en afbreekbaar. Voor een computer is elke letter een teken, een informatiecombinatietje, data. Zet iemand ze op een rij, dan komen er zinnen te- 
voorschijn, die betekenis kunnen krijgen: een band aangaan met de wereld buiten de computer. Want betekenis komt altijd van twee kanten, en ik ben geen computer.

Op een scherm vormen de woorden de interface naar een romanwereld achter de tekst, waarin ook ik, de lezer, leef voor zolang ik het e-book lees of eraan denk. Op papier vormen de woorden kettingen, buizenstelsels waar betekenis doorheen wordt gepompt. Het is een dwingend medium, het papieren boek, met z'n materiële verschijningsvorm die ruimte en zorg eist. Een papieren boek kopen is om moeilijkheden vragen, het ding dient geestelijk overwonnen te worden om het zijn magische kracht te ontnemen. Elk onuitgelezen papieren boek drukt op het geweten van de lezer, want het moet worden bewaard voor de dag dat het toch nog uitgelezen zal worden. Wat Rem Koolhaas noemt: junk space. Troep, rommel, geen afval. Afval is weggegooid. Rommel wacht op hergebruik. Een boekenkast is als oma's vliering waar onvoorziene ontdekkingen wachten in vooroorlogse hutkoffers. Het deurtje naar Narnia en terug. Naar de slag bij Waterloo door de ogen van Stendhal. Moskou bij Tolstoi. Slauerhoffs China. Vaandragers Rotterdamse mens.

Dus een e-reader vol gratis pulpverhalen en een enkel aangeschaft literair werk - zeg de verzamelde werken van Kafka voor €2,95 in de Delphireeks - verlicht het lezersgeweten alleen al door z'n immateriële want digitale archivering. Het apparaat meldt weliswaar pedant hoeveel procent je al achter de kiezen hebt en hoeveel uur onbekommerd of volhardend lezen er nog voor je liggen, maar bij niet-lezen doet het daar niet moeilijk over en verdwijnt het boek als vanzelf naar de achtergrond, richting Borges. Een e-reader is niet alleen een boek, maar ook een bibliotheek met eigenwijs personeel en al. Het is een ruimte vol 'twintig uren lezen te gaan' zoals mijn kobo-reader kromspreekt: een ruimte vol tijd die nog geleefd mag worden.

Een boek is een blok tijd. Het is, als afgerond verhaal ofwel gesloten medium, een verstard fragment uit de historische tijdstroom, die weer op gang komt zodra jij het door lezen tot leven wekt. Het brengt een tijdstroom tot een einde. Een boek lezen is geen risicoloos entertainment, het zijn altijd jouw persoonlijke hersenen die gekitteld gaan worden, en eenmaal op gang kunnen die op ideeen komen waar geen bezadigdheid of gedweeheid tegen bestand is.

Als de e-reader van iedereen voortaan een grafisch ontwerper maakt, roept dat een probleem in het onderwijs op: wat maak je precies als je iets ontwerpt? Grafische vormgeving is een inhoudsfilter uit het tijdperk van de papieren reproductie. De kei- zerlijke order diende in vettig gotische typografie te worden uitgevaardigd, het keizerrijk in drie kleuren verheerlijkt. Wat is een boek zonder vormgever? Dat de democratisering van de grafische vormgeving een vervlakking van het leesgedrag tot gevolg zal hebben - bij mij in elk geval niet. Stifters Nachsommer kwam loepzuiver over en transformeerde ook mij in een Biedemeierse schoonheidsadept.

Twee-nul voor de e-reader: flexibele vormgeving, bibliotheek in plaats van afzonderlijk boek. En daar komt, ten derde, bij dat een e-reader ook een e-shop is, waar je ergens in Moravië in een hotelletje met wifi gewoon deel drie en vier kunt aanschaffen van de drakenjagerslegende die je zoon van elf juist heeft verslonden op zijn e-reader, de eerste in ons gezin. Hij had er zin in, zette het ding razendsnel vol gratis downloads. Leest praktisch alles wat hij erop krijgt. Heeft nu ontdekt dat je er via een omweg toegang mee kunt krijgen tot internet.

Participerende observatie. Het gezin bestaat uit drie personen. De zoon van twaalf heeft al ruim een jaar een e-reader, de vader een paar maanden, de moeder heeft sinds kort een nieuwer model kobo, met schermverlichting en naar verluidt minder omslachtig in gebruik. De kobosite blijkt niet in staat onze drie readers uit elkaar te houden, zodat we alle drie al onze boeken meedragen, wat ook weer handig kan zijn in voorkomende gevallen. We zitten in pension Varnik in Horni Lipova aan de beboste grens van Tsjechië en Polen. Meldt mijn e-reader opeens, na wat geblikker, iets als: Re-initialising. Wat betekent dat? vraag ik verschrikt. Mijn zoon: Dat je alles kwijt bent, pa. Dat was ook zo, maar verrassend genoeg begon mijn e-reader zich toen zelf weer te hersynchroniseren, en plaatste al mijn bij kobo gekochte boeken terug op mijn reader. De bij anderen aangeschafte of gedownloade boeken waren verdwenen. Die staan nog thuis op de harde schijf, zegt kenner zoon, en daar vond ik ze ook, zij het pas na de vakantie. Maar die andere boeken, de kobo's? Waar komen die zo snel vandaan, vraagt Maaike. Door een telefoondraadje? Door de lucht? Het is een beetje griezelig, het gaat toch om complete oeuvres die je zomaar even kwijt was.

\section{DE VOORS EN TEGENS}

De e-reader hielp allicht bij mijn besluit deze zomer Stifters Der Nachsommer te lezen. Ik had me de klassieker altijd meer voor na mijn pensioen voorgesteld, maar blijkbaar was ik er nu aan toe. Ik heb het thuis in een mooie Oost-Duitse uitgave staan, maar ik kan er niet toe komen een van de vijf bandjes te knakken om de in socialistisch font gezette tekstblokken tot mij te nemen. Het cadeau van mijn e-bookprovider (Der Nachsommer kon ik gratis 
downloaden) voegde een laag van generositeit toe aan de leeservaring. Stifter beschrijft zijn tijd en wereld in een bizar abstract Duits, die de roman op spanning houdt, wegleggen is er niet bij. Stel dat iemand zich helemaal harmonisch ontwikkelt, ongehaast, organisch, alles gaat precies goed en zoals het hoort... Wat verwerft zo iemand dan aan inzichten als hij in een lange leerweg ten slotte ook de kunst leert begrijpen en ervaren? En wat weet hij over schoonheid, en dat is in Stifters kolossale roman een absoluut waardeoordeel met financiële consequenties.

Der Nachsommer is ook een bron van informatie over de eerste generatie cultuurbehouders in Oostenrijk, private herstellers van middeleeuwse kerkjes. De geboorte van de monumentenzorggedachte. Adalbert levert er de complete theorie en standpunten bij. Met kunst ga je fatsoenlijk om, dat is het uitgangspunt. Je doet er niet extatisch over, maar bestudeert het aandachtig: drie dagen om één schilderij van Titiaan te bekijken is geen uitzondering. Der Meister der Langsamkeit.

En ja, hoe lang kijken wij naar een foto? Hoe vaak en versnipperd? Eén seconde, twee keer misschien? En hoe lang lukte het die naakte vrouw of dat heerlijke mannenlichaam om zo mooi te blijven als ze eruitzien op deze glamourfoto - een duizendste seconde? Schoonheid is op het continent van de snelheid waar wij leven iets wat je uit de tijdstroom grist en intensiveert: dat ene goede beeld uit de kolkende stromen van middelmatige plaatjes. Bij Stifter ontwikkelt het schoonheidsbesef zich met de tijdstroom mee, het kost een jaar of tien studie voordat de held snapt wat er te zien valt op de schilderijen in het ouderlijk huis waar hij zijn leven lang al bijna dagelijks langs loopt. Niemand die hem dwingt er kunst in te herkennen. Op een dag komt het vanzelf. Je aansluiten op de ruimte van de kunst, een tuin of woning of schilderij of standbeeld, versus: heel even ontroerd raken door een moment van herkenning of afstoting, en dan weer verder 'swappen'.

Over de abstracte blik van Adelbert Stifters held legt het leesscherm van de e-reader een technologische laag en creëert zo afstand tot de woordelijke tekst, waarin een vorige generatie kon verzinken, terwijl ik met mijn technische blik van een afstandje geniet van hoe de schrijver zijn zinnen laat ontvouwen, als bergbeekjes vertakken en weer samenvloeien. Het is de blik van de man die het hooggebergte heeft beklommen en vanaf de uiterste top het laagland overzag. De lezer hoeft het niet met de schrijver eens te zijn om te genieten van diens argumentatielijnen. Meer dan een miljoen loepzuivere woorden, nooit een wanklank, nooit gehuichel, over hoe een mens naar beelden leert kijken en er de kunst in herkent, en de schoonheid. En de consequenties. Der Nachsommer is ook een boy meets girl verhaal in Biedemeierstijl. Toen alles nog beleefd toeging in de sociale omgang...

Terug naar onze argumentatielijn. Vier-nul voor de e-reader, zou ik zeggen. 1) Iedereen een grafisch vormgever, 2) bibliotheek, 3) e-shop, en dan als 4 ) de extra laag abstractie die het apparaat aan de leeservaring toevoegt, waardoor je zinnen leest in plaats van situaties. Dat was voor mij nieuw, dat kende ik niet van het papieren boek, waarvan ik er toch vele heb gelezen.

Het is hoog tijd ook de nadelen van het apparatieve lezen te verkennen. Ik noemde er al een: het kan zichzelf onverwacht initialiseren en dan ben je alles kwijt en krijg je alleen het eigen product van je e-readprovider op je persoonlijke leestoestel terug geseind - een proces dat een beetje spooky is. De dematerialisering van het boek voelt niet honderd procent koosjer, het is als wat Kafka over zoenen via de telefoon zei: het apparaat zuigt er het beste deel uit weg. Vier-één.

Een nadeel is ook de anonimiteit van het technische apparaat. Veel variatie valt er qua uitvoering niet in te ontdekken. Het papieren boek met zijn tot op enige afstand leesbare titel biedt affordances voor wegfantaseren. Wat voor Franse verfijning gaat er schuil achter de titel La vie est brève et le désir sans fin, dat die goed gekapte vrouw van een jaar of dertig tegenover je in de metro zit te lezen? Heel even is ze subliem in haar zichzelf-genoeg-zijn met haar boek, maar zodra ze opkijkt is ze weer gewoontjes. Het leven is niet kort, hoe komen ze erbij? En was ons verlangen maar wat oneindiger. Argument: de laag van onuitgesproken communicatie via boektitels tussen de aanwezigen in een semi-openbare ruimte valt weg bij verbreiding van de e-reader. Kwaliteitsverlies van het publieke leven van de verbeelding: vier-twee.

Over vier-drie en vier-vier kunnen we kort zijn. Een e-reader is een instabiel medium. Het kan zich spontaan her-initialiseren, maar ook in de lopende tekst treden rare verspringingen op. Klopt de transcriptie wel? In Knausgårds 'e-Vader' zit opeens een pagina of twintig experimenteel proza - heel interessant tussen al dat gedegen realisme - maar of dat de bedoeling is? Bij een uitgever die ook zulke lelijke omslagen maakt weet je maar nooit. Je hebt als e-booklezer geen zekerheid over de status van de tekst, je krijgt geen garantie op correctheid. Dat interfereert met de leeservaring zodra er iets vreemds gebeurt in de lopende tekst, wat dan ofwel hoogst belangrijk is, ofwel een technische storing. Dus drie: de instabiliteit van de tekstdrager. En vier: de instabiliteit van de leeserva- 
ring. 'The suspension of disbelief' strekt zich voortaan ook uit tot het tekstmedium zelf. Je gelooft wat je leest tot je er niet meer in gelooft. De e-reader maakt elk tekstueel experiment verdacht. Wat is het verschil tussen een literaire ingreep en een bug? Wat lees ik eigenlijk?

Een papieren boek is een middel om je van de buitenwereld af te schermen. Een beeldscherm is een middel om de wereld naar je toe te halen. Als iedereen op wifi zit in de metrocoupé zal het net zo spannend kunnen worden als in de tijd van de onuitgesproken communicatie via blikken, gebaren, geurtjes en soms een schuchtere glimlach (dag goed). Stiekem berichtjes versturen... Maar wie leest er dan nog in het openbaar? Karakteristieke dialoog uit de overgangstijd van papieren boek naar e-reader en terug, in een boekenwinkel op Bristol Airport: 'No mums, me eyes are hurting from reading on my iPhone, I want Wuthering Heights on paper.' En ze vindt het boek ook nog. Wat verliezen we, wat winnen we als het boek een privé-object wordt en het leesapparaat de standaard? Een leesapparaat dat ook een winkel is en aansluiting op internet heeft, kortom, van smartphone en iPad alleen te onderscheiden is door z'n historische, op jaszak afgestemde formaat?

Ik laat de toekomst graag aan glazen bollen. Misschien lezen binnenkort alleen de allerrijksten nog van papier, of juist de allerarmsten, wat me waarschijnlijker lijkt. De middenklasse in Engeland is al massaal aan de e-reader. De eerste e-reader die ik in het wild zag dook in de Amsterdamse metro op uit de wijde broekzak van een Engelse werkman die zo te zien actief was in de bouw. Met zijn doorgroefde handen zette hij teder het apparaat aan en las voor mijn verbaasde ogen in wat een boeiend boek moest zijn. Zo gaat dat dus, dacht ik. Een week later kocht ik er zelf een.

Het eerste e-book dat ik op mijn kobo las, was Tonio van A.F.Th. van der Heijden. De combinatie van apparatieve intimiteit en intellectuele afstand van de e-reader hield het ondraaglijke verhaal over de dood van zijn zoon leesbaar, in porties van tweemaal per week een uur in de trein. Ik zou nooit begonnen zijn aan het papieren boek. Door zijn omvang en gewicht legt dat een leesregiem op waar $\mathrm{ik}$ niet aan wil. Een e-reader is minstens zo intiem als een boek, zonder dat je daar en public voor uit hoeft te komen. Trouwens, stiekem gluren welk boek de knappe vrouw tegenover je zit te lezen kan als hinderlijk worden ervaren, geilig ouwemannengedrag, naar ik constateer. Dan liever zo'n dofzwarte e-reader, zoals daar aan het eind van het gangpad, vastgeklemd onder twee overigens prachtige borsten, voor wat ervan te zien wordt gegeven. Ik lees.

\section{EERSTE ANTWOORDEN}

De stelling van Marshall McLuhan dat het boek bij verandering van medium, ofwel de overgang van papier naar scherm, tot een compleet andere leeservaring moet leiden, kan ik op grond van bovenstaand onderzoek beamen. Bij het papieren boek vallen inhoud en medium samen: per boektekst wordt één exemplaar geleverd, met één vormgeving, één typografie. Bij het e-book vallen inhoud en medium niet langer samen en kunnen dus vele boekteksten in vele formats per e-reader worden geleverd. Dat leidt tot belevenissen zoals boven beschreven, al vormen die slechts het begin van de exploratie van deze nieuwe leeswijze. Een ervaring van mijzelf lezend als knooppunt van een netwerk het elektronische ik-besef - daar heb ik slechts terloops iets van gemerkt, vermoedelijk vooral omdat ik mijn e-reader zo gesloten mogelijk gebruik, dus zonder internettoegang (tenzij de e-reader zelf me daartoe verplicht).

Afgelopen zomer bezoeken we Polen, en ik download voor de gelegenheid een zojuist verschenen vertaling van een Poolse klassieker, De pop van de mij onbekende Boleslav Prus. Ik zet de tekst onmiddellijk om, als was ik een kenner, in de Gill Sans waarin ik Der Nachsommer had belopen. Ditmaal leidt de beitelharde typografie tot een stotterige, dan weer stroperige lectuur, alsof het marmer verrot is. Ik schakel om op de realistische Georgia, rond met schreef, en ja, daar verschijnt het Warschau van 1890. Ik lees het e-book in de slaaptrein, voor het gloeiend hete station Warschau, in Bialowiezca met het bos en Augustow met de meren in een kleine tien dagen uit, terwijl we overdag veel wandelen en zwemmen. Ik kuier door de roman heen met dezelfde toeristische blik als waarmee ik het landschap en de bevolking aanschouw. Het effect van er-is-alleen-maar-heden van het e-book is zo sterk dat ik de vele pagina's nog te gaan nooit als last of opdracht beschouw, maar gewoon doorlees, nu, telkens weer nu in de late negentiende eeuw met zijn drama's van stand en menselijk fatsoen.

Ik sta iedere keer weer paf als ik ergens in een boekhandel een papieren exemplaar van De pop zie liggen. En dat heb ik onbekommerd in anderhalve week uitgelezen, zonder ooit het gevoel te hebben van voort te moeten, puur genoegen, en dat terwijl het een verhaal is over liefde als grootste onderdrukkende kracht in de maatschappij!

Stel dat we het woord leeservaring (als iets wat je ondergaat) vervangen door het idee van de leesstrategie (als iets wat je besluit te hanteren). Ik opperde dit aan mijn studenten Editorial Design aan de Master HKU en één van hen, Ana Caterina 
Rodriguez uit Lissabon, deed hier onderzoek naar en constateerde dat je als lezer uit maar liefst vijf verschillende leesstrategieën kunt kiezen. Ze noemde ze, naar analogie van Roland Barthes' modes of writing (écritures) modes of reading, manieren waarop het leespubliek een tekst contextualiseert en interpreteert, afhankelijk van het medium of platform waarin het de tekst leest. Dit zijn de keuzes:

Deep reading doe je met teksten waarvan je alle lagen wilt exploreren, met concentratie, aandacht, herlezen, aantekeningen maken in marges - best geschikte medium: het boek (gedrukt of e-book).

Speed reading is het diagonaal doornemen van een tekst om te zien of er voor jou belangrijke informatie in staat, eventueel ter voorbereiding op deep reading - medium: boek in druk (doorbladeren).

Light reading: de blik springt van alinea op alinea over op zoek naar interessante passages, zoals bij het lezen van een krant of tijdschrift.

Scan reading: het oog tasten een tekst af op zoek naar relevante begrippen of citaten, zoals op een website waar je specifieke informatie hoopt te vinden.

En hyper reading: het lezen van passages die je via hyperlinks met elkaar verbindt.

Herken je je leesgedrag als een verzameling strategieën waar je naar believen gebruik van kunt maken, dan heb je als lezer een wapen in handen tegen de argumentatieve of stilistische overmacht van een tekst die je helemaal in haar ban houdt. Je bent ieder moment vrij op een andere reading mode om te schakelen. Waar deep reading tot depressie leidt, kan scan reading van dezelfde tekst de grijze cellen juist prettig activeren. De lezer is niet het slachtoffer van het geschrevene, of de medeplichtige, maar de navigator, de kapitein op het gammele bootje van de hoogstpersoonlijke leeservaring met minimaal vijf leesversnellingen.

Het papieren boek is van oudsher de drager van de deep reading mode. Je slaat het op je nachtkastje dicht en morgenavond stap je zo weer in, precies waar je gebleven was. Het papieren boek is een geheugenproducent. Het e-book heeft dat minder, waar het de details betreft. Maar het abstracte topgeluksgevoel dat het opriep, Adalbert Stifters besef van wat kunst is, of bij Boleslav Prus, wat een buitenstaander normaal vindt en wat niet, is sterker blijven hangen dan ik me van een epos van Harry Mulisch of George Eliot herinner. Het nu is een abstractie. In plaats van op eigen kracht te zwemmen, drijf je met een e-book mee op de stroom van de woorden. In het gedrukte boek ervaar je sterker de continuïteit van de wereld, met een e-book versterk je het nulpunt daarbin- nen, daar waar jij staat in de tijd.

Ik zet zojuist mijn kobo e-reader aan, waarvan ik me opeens herinner dat ik die onlangs onbedachtzaam heb laten re-synchroniseren met nieuwe software, kobo 3.o, en nu merk ik dat het menu achter het scherm, dat tevoorschijn kwam als je er lang met je duim op duwde, verdwenen is. Het is niet langer mogelijk zelf het lettertype te bepalen. De typografen slaan terug! Al mijn e-books, ook degene die ik al uit heb, blijken in dezelfde Helvetica-achtige schreefloze letter te zijn omgezet. Diefstal! Ik wil mijn fonts terug!

Kobo beschouwt mijn e-books niet als objecten die ik van ze heb gekocht, inclusief die acht fonts waarmee ik mijn user-experience kan optimaliseren. Zij zien ze als een service die zij leveren. Ik heb bij hen mijn e-books geleasd, ze blijven in hun bezit. Dat graaft zich zomaar dwars door mijn e-reader heen, zonder mij zelfs maar de optie te laten kobo 3.0 te accepteren of het oudere programma te handhaven. Ik ben de zeggenschap over mijn e-reader kwijt. De user-interface is net zo instabiel en onbetrouwbaar geworden als de gebruikte tekstedities. Dit ergerniswekkende besef, waar het apparaat me keihard met mijn neus op drukt, ken ik niet van het gedrukte boek, zelfs niet als het lettertype een te overwinnen leesobstakel vormde, of het papier naar sigaar stonk. Als ik nu een e-book op mijn e-reader lees doe ik dat als de gevangene van kobo, die zich voor haar bewaking van mij ook nog eens flink laat betalen.

\section{BIOGRAPHY}

Arjen Mulder is bioloog en essayist. Hij publiceerde vanaf 1990 een reeks studies waarin hij telkens de invloed van een bepaald technisch medium op onze ervaring van de wereld en op onze intiemste gevoelens analyseert en die hij verzamelde in: Het fotografisch genoegen (2000), Over mediatheorie: taal, beeld, geluid, gedrag (2004) en Van beeld naar interactie: betekenis en agency in de kunsten (2010). Zijn essayistische methode oogstte lof in binnen- en buitenland. Arjen Mulder doceert mediatheorie en semiotiek aan de KASK in Gent en Codarts in Rotterdam.

\section{KEYWORDS}

\author{
- mediatheorie \\ - e-book \\ - McLuhan \\ - leesgewoonten \\ - media-environment
}

